\title{
Spectrum and Immediate Outcome of Acute Kidney Injury in a Pediatric Intensive Care Unit: A Snapshot Study from Indian Subcontinent
}

\author{
Ashwini Bharat ${ }^{1}$, Anita Mehta ${ }^{2}$, Harish Chandra Tiwari ${ }^{3}$, Bhupendra Sharma ${ }^{4}$, Abhishek Singh $^{5}$, Vijay Singh $^{6}$
}

\section{Abstract}

Background and aims: Acute kidney injury (AKI) became an important cause of mortality and morbidity in critically ill children, despite advancement in its management. In developing countries etiology of AKI are different from that of developed countries.

Materials and methods: This observational study was carried out in pediatric intensive care unit (PICU) in 2 months to 18 years of critically ill children. Kidney injury was defined and categorized by the PRIFLE criteria.

Results: Out of 361 children, 86 children (23.8\%) developed AKI at some point during admission, 275 children (age and sex matched) who did not develop kidney injury during hospitalization served as non-AKI children. Maximum cases of AKI were seen in 1-5 years of age. Maximum children of AKI were of viral encephalitis $(n=43,50.0 \%)$ followed by scrub typhus ( $n=14,16.3 \%)$. Risk factors for the development of AKI were shock, PRISM score and longer hospital stay. In our study the mortality in AKI children ( $\mathrm{n}=30,34.8 \%)$ was significantly higher $(p=0.005)$ as compared to non-AKI children $(n=56,20.3 \%))$. Duration on mechanical ventilation, PICU stay and hospital stay were also significantly $(p=$ 0.001 ) higher in AKI children.

Conclusion: AKI is common in critically ill children and associated with high mortality and morbidity.

Keywords: Acute kidney injury (AKI), Pediatric intensive care unit (PICU), pRIFLE, Viral encephalitis, Scrub typhus

Indian Journal of Critical Care Medicine (2019): 10.5005/jp-journals-10071-23217
\end{abstract}

\section{INTRODUCTION}

Acute kidney injury (AKI) is a leading cause of morbidity and mortality in critically ill children. AKI is characterized by the abrupt deterioration of renal functional resulting from retention of endogenous or exogenous toxic metabolites which leads to reduction in glomerular filtration rate (GFR), rise of serum creatinine (SCr) and fluid, electrolyte and water imbalance. ${ }^{1}$ The incidence of AKI varies between $10 \%$ and $45 \%$ in different countries among different ethnic children. ${ }^{2,3}$ Despite advances in management of critically ill children, the mortality of AKI children is still high (30-40\%) and a proportion of children may progress to chronic kidney disease (CKD). There are different methods for diagnosis and grading of AKI. ${ }^{4}$ pRIFLE criteria is commonly used for diagnosis, grading and prognosis of AKI. ${ }^{5}$

Burden and spectrum of AKI in developing countries is different from that of developed countries. ${ }^{2,6}$ In developed countries the underlying cause is predominantly postsurgical, malignancy, and nephrotoxic drugs and in developing countries, it is due to severe infection, diarrhea, hemolytic-uremic syndrome and glomerulonephritis. ${ }^{5,7,8}$ There is lack of literature of AKI in eastern UP, hence this study has been planned to know the burden, etiology and immediate outcome of AKI among hospitalized children in pediatric intensive care unit (PICU) of tertiary care hospital which would help in identifying the possible areas of intervention.

\section{Materials and Methods}

\section{Setting, Design and Duration of Study}

Study setting: PICU, Department of Pediatrics, BRD Medical College, Gorakhpur, Uttar Pradesh. $\overline{{ }^{1} \text { Department of Pediatrics, Christian Medical College, Vellore, Tamil }}$
Nadu, India
${ }^{2,4-6}$ Department of Pediatrics, BRD Medical College, Gorakhpur, Uttar
Pradesh, India
${ }^{3}$ Department of SPM, BRD Medical College, Gorakhpur, Uttar Pradesh, India

Corresponding Author: Anita Mehta, Department of Pediatrics, BRD Medical College, Gorakhpur, Uttar Pradesh, India, Phone: 919450883855, e-mail:25anitamehta@gmail.com

How to cite this article: Bharat A, Mehta A, Tiwari HC, Sharma B, Singh A, Singh V. Spectrum and Immediate Outcome of Acute Kidney Injury in a Pediatric Intensive Care Unit: A Snapshot Study from Indian Subcontinent. Indian J Crit Care Med 2019;23(8):352-355.

Source of support: Nil

Conflict of interest: None

Study design: Cross-sectional hospital-based study.

Study duration: July 2017 to October 2017.

\section{Sample Size}

Sample size was calculated by using formula $4 \mathrm{PQ} / \mathrm{L} 2$. The incidence of AKI varies between $10 \%$ and $45 \%$ in different countries among different ethnic children. Records at our centre reveals 30-40\% incidence of AKI among children admitted in PICU. Calculated sample size was 336 by considering proportion of children admitted in PICU developing AKI as $30 \%(p=30 \%)$ with an allowable error (L) of 5\%. We included 30\% extra for non/incomplete responder/ deaths/other reasons for exclusion. Final sample size taken for screening was 436.

(0) The Author(s). 2019 Open Access This article is distributed under the terms of the Creative Commons Attribution 4.0 International License (https://creativecommons. org/licenses/by-nc/4.0/), which permits unrestricted use, distribution, and non-commercial reproduction in any medium, provided you give appropriate credit to the original author(s) and the source, provide a link to the Creative Commons license, and indicate if changes were made. The Creative Commons Public Domain Dedication waiver (http://creativecommons.org/publicdomain/zero/1.0/) applies to the data made available in this article, unless otherwise stated. 


\section{Inclusion and Exclusion Criteria}

All children admitted in PICU from 2 months to 18 years of age were enrolled for the study. Criteria for admission in PICU were need of mechanical ventilation, vasopressor support, having respiratory failure, fulminant hepatic failure and poorly controlled seizure. Post surgical children and children with oncological emergencies were not admitted in our PICU. Children who were less than 2 months of age, having CKD, PICU stay $<24$ hours and with major congenital anomaly were excluded from the study.

\section{Study Procedure}

The study protocol was approved by the Institutional Ethics Committee. Well informed written consent in local language after explaining them the purpose of study was taken from mothers/ guardians of each child. Children admitted in PICU fulfilling the inclusion criteria were enrolled. A detailed evaluation was done in all the children to ascertain the etiology, its progression and need for dialysis of AKI. PRISM III score was used for assessment of severity of illness during the first 24 hour of admission. ${ }^{9}$ All the children were managed according to standard management protocol. They were followed until discharge from PICU and then from hospital to determine recovery of renal function and need of renal replacement therapy (RRT). Indications for RRT were anuria or oliguria with shortness of breath, intractable metabolic acidosis, difficult to control hypertension, features of uremia, altered sensorium, severe hyperkalemia and recurrent vomiting in the setting of rise in serum creatinine. $^{10}$

Serum creatinine and biochemical tests were done in departmental side lab. Serology for dengue, Japanese encephalitis (JE), scrub typhus, herpes virus and measles were done in Regional Research Centre of National Institute of Virology (NIV) Pune, situated in premises of our Institute. All the findings were recorded on a predefined working proforma.

Outcome measures in our study were need and duration of invasive mechanical ventilation, duration of stay both in the PICU and in hospital, and mortality.

\section{Assessment of Kidney Injury}

Kidney injury was defined and categorized using the pRIFLE criteria. ${ }^{5}$ Maximum pRIFLE stage during PICU stay was recorded with special emphasis on time of onset and duration of kidney injury. Children, who did not develop AKI during stay at PICU, were taken as control. Baseline estimated $\mathrm{CCl}$ was calculated from serum creatinine measured within 3 months before PICU admission. In the absence of baseline creatinine, $100 \mathrm{~mL} / \mathrm{min} / 1.73 \mathrm{~m}^{2}$ was considered to be baseline eCCl. Serum creatinine level was estimated by auto analyzer by modified Jaffe method. ${ }^{11}$ It was done at admission and then daily, sometimes more frequently depending on patient's clinical condition. The $\mathrm{CCl}$ was estimated from the Schwartz formula. $^{12}$

$$
\mathrm{ECCl}=\mathrm{K} \times \text { Height }(\mathrm{cm}) / \mathrm{SCr}
$$

$\mathrm{K}$ : Constant, its value is 0.45 in $<12$ months, 0.55 in 1 and 12 years, 0.55 in females $>12$ years and 0.70 in males $>12$ years. eCCl more than $90 \mathrm{~mL} / \mathrm{min} / 1.73 \mathrm{~m}^{2}$ was considered normal. We classified AKI according to change in eCCl of children. Urine output criteria was not used in our study because it is affected by hydration state, use of diuretics, amount of intravenous fluid, and presence of obstruction.

\section{Statistical Analysis}

SPSS version 22 (Armonk NY, IBM Company) was used for statistical analysis. Descriptive data were presented as percentages, means, and standard deviation. Chi-square test was used to study frequency distribution between children and when frequency was less than 5 Fisher's exact test was used. Independent sample "t" test was used to compare means of AKI and non-AKI group. Binary logistic regression analysis has been done to find out risk ratio of important risk factors. $p$ value $<0.05$ was considered significant.

\section{Results}

A total of 436 children were screened on admission, out of which 75 were excluded (12 CKD on admission, 3 congenital anomaly, 42 had $<24$ hour PICU stay and 18 refused to participate in study). Out of 361 who met the inclusion criteria, 86 children (23.8\%) developed AKI at some point during admission, and of these $46(53.4 \%)$ were reached as risk $\left(R_{\max }\right), 24(28 \%)$ as injury $\left(I_{\max }\right)$, and $16(18.6 \%)$ as failure $\left(F_{\max }\right)$ grading. Two seventy five children (age and sex matched) who did not develop kidney injury during hospitalization served as non AKI children. Mean \pm SD PRISM III scores for non AKI, $R_{\text {max }} I_{\text {max }}$, and $F_{\text {max }}$ grading was $3.89 \pm 5.65,6.3 \pm 2,7.2 \pm 2.8$ and $9.8 \pm 2.7$ respectively.

The mean age of AKI and non-AKI children were $5.6 \pm 3.4$ and $5.9 \pm 3.2$ years respectively. Male: Female ratio in AKI and non-AKI children was 1:1.3 and 1:1.1 respectively. Baseline characteristics of AKI and non-AKI children were comparable (Table 1). Nephrotoxic drugs used in our PICU were aminoglycosides, vancomycin and loop diuretics with a mean duration of 5 days.

Table 2 showing distribution of AKI and non-AKI children according to etiology. Maximum children in our PICU were of viral encephalitis ( $n=145,40.16 \%)$, followed by scrub typhus ( $n=104$, 28.8\%). The children of viral encephalitis and scrub typhus together constituted more than half of total cases. Viral encephalitis included suspected and confirmed cases of dengue, JE, herpes and measles. Maximum children of AKI were also of viral encephalitis $(n=43$, $50.0 \%$ ) followed by scrub typhus ( $n=14,16.3 \%$ ).

In Table 3, we estimated risk ratio of the risk factors responsible for AKI by logistics regression analysis. We found shock (RR 5.041; $p=0.014$ ), PRISM III score (RR 0.392; $p=0.000$ ) and hospital stay

Table 1: Baseline characteristics of AKI and non-AKI children

\begin{tabular}{|c|c|c|c|c|}
\hline \multicolumn{2}{|c|}{ Baseline characteristics } & $\begin{array}{l}A K I \\
n=86( \pm S D)\end{array}$ & $\begin{array}{l}\text { Non- } A K I \\
n=275( \pm S D)\end{array}$ & $p$ value \\
\hline \multicolumn{2}{|c|}{ Average age (years) } & $5.6 \pm 3.4$ & $5.9 \pm 3.2$ & 0.53 \\
\hline \multicolumn{2}{|c|}{ Average weight (kg) } & $15.4 \pm 3.6$ & $17.4 \pm 6.5$ & 0.14 \\
\hline \multicolumn{2}{|c|}{ Average height (cm) } & $106.5 \pm 3.4$ & $108.2 \pm 6.2$ & 0.12 \\
\hline \multirow[t]{2}{*}{ Gender } & Male & 49 (56.9\%) & 144(52.3\%) & 0.45 \\
\hline & Female & $37(43.1 \%)$ & 131 (47.7\%) & 0.45 \\
\hline \multicolumn{2}{|c|}{ Nephrotoxic drugs ( $n=$ ) } & $42(48.8 \%)$ & $126(45.8 \%)$ & 0.62 \\
\hline
\end{tabular}

Table 2: Distribution of AKI and non-AKI children according to etiology

\begin{tabular}{llll}
\hline Etiology & $\begin{array}{l}\text { AKI } \\
(n=86, \%)\end{array}$ & $\begin{array}{l}\text { Non-AKI } \\
(n=275, \%)\end{array}$ & $\begin{array}{l}\text { Total } \\
(n=361, \%)\end{array}$ \\
\hline Viral encephalitis & $43(50 \%)$ & $102(37 \%)$ & $145(40.2 \%)$ \\
Scrub typhus & $14(16.3 \%)$ & $90(32.8 \%)$ & $104(28.8 \%)$ \\
Sepsis & $12(14 \%)$ & $13(4.7 \%)$ & $25(6.93 \%)$ \\
Gastroenteritis & $10(11.7 \%)$ & $8(3 \%)$ & $18(4.99 \%)$ \\
Diabetes mellitus & $2(2.3 \%)$ & $24(8.8 \%)$ & $26(7.20 \%)$ \\
Tubercular meningitis & $3(3.4 \%)$ & $21(7.6 \%)$ & $24(6.65 \%)$ \\
$\begin{array}{l}\text { Hepatic encepha- } \\
\text { lopathy }\end{array}$ & $2(2.3 \%)$ & $17(6.1 \%)$ & $19(5.26 \%)$ \\
Total & $86(100 \%)$ & $275(100 \%)$ & 361 \\
\hline
\end{tabular}


Spectrum and Immediate Outcome of Acute Kidney Injury in a Pediatric Intensive Care Unit

Table 3: Multivariate analysis of AKI and non-AKI children

\begin{tabular}{lllll}
\hline Variables & $A K I$ & Non $A K I$ & & \\
\hline Shock & $n=86(\%)$ & $n=275(\%)$ & $P$ value & $R R$ \\
PRISM III score & $78(55.8 \%)$ & $68(24.7 \%)$ & 0.014 & 5.041 \\
$\begin{array}{l}\text { Hospital stay } \\
\text { (days) }\end{array}$ & $7.7 \pm 2.3$ & $5.5 \pm 1.6$ & 0.000 & 0.090 \\
\hline
\end{tabular}

Table 5: Outcome and grading of AKI

\begin{tabular}{lllll}
\hline & $\begin{array}{l}\text { Risk } \\
(n=46,\end{array}$ & $\begin{array}{l}\text { Injury } \\
(n=24,\end{array}$ & $\begin{array}{l}\text { Failure } \\
(n=16,\end{array}$ & \\
Variables & $53.5 \%)$ & $27.9 \%)$ & $18.6 \%)$ & $p$ value \\
\hline $\begin{array}{l}\text { Mechanical ventilated } \\
\text { ( } \mathrm{n}=43)\end{array}$ & $13(28 \%)$ & $17(70 \%)$ & $13(81 \%)$ & \\
$\begin{array}{l}\text { Duration of ventilation } \\
\text { (days) }\end{array}$ & $4.3 \pm 0.59$ & $5.2 \pm 1.3$ & $5.2 \pm 1.8$ & 0.0002 \\
PICU stay (days) & $5.5 \pm 2$ & $6.7 \pm 2$ & $8 \pm 2$ & 0.0001 \\
Hospital stay (days) & $6.8 \pm 1.8$ & $7.5 \pm 1.6$ & $9 \pm 1.7$ & 0.0004 \\
\hline
\end{tabular}

(RR 0.090; $p=0.000$ ) as risk factors for the development of AKI in our patients.

We found $33.6 \%(n=29)$ children developed AKI within 24 hours of hospitalization. Maximum cases ( $n=54,63 \%)$ developed AKI between 1 day and 7 days and only 3 (3.4\%) children developed after 7 days. All of the children developed AKI during PICU hospitalization. RRT was required in 11 (16.1\%) children. Two children of $\mathrm{R}_{\max }(4.35 \%)$, 4 of $I_{\max }(16.67 \%)$ and 5 of $F_{\max }(25.0 \%)$ grading required RRT.

In our study (Table 4) the mortality in AKI children ( $n=30,34.8 \%)$ was significantly higher $(p=0.005)$ as compared to non AKI children $(n=56,20.3 \%))$. The duration on mechanical ventilation, PICU stay and hospital stay were also significantly $(p=0.001)$ higher in AKI children than in non-AKI.

In Table 5, outcome measures were compared with AKI grading. There is statistically significant difference for hospital stay ( $p=$ $0.0004)$, PICU stay ( $p=0.0001)$ and for duration on mechanical ventilation ( $p=0.0002$ ) with severity of AKI grading.

\section{Discussion}

This study was carried out in a tertiary care hospital to know the spectrum, etiology and immediate outcome of AKI among hospitalized children in PICU from 2 month to 18 years of age during a specified period of tine i.e. from July to October. The incidence of AKI in our PICU children was $23.8 \%$. The incidence of AKI in different studies varied between $6.2 \%$ and $42.9 \% .{ }^{13-21}$ This varied incidence may be because of different ethnic group, different inclusion criteria for study, different admission criteria in PICU, varied etiology of critically ill children, varied risk factors and inconsistent use of AKI classification criteria. Some authors had used AKIN criteria and others pRIFLE criteria. In pRIFLE criteria also some had used both $\mathrm{eCCl}$ and urine output criteria and others only eCCl criteria.

Our study showed a very distinct distribution of disease etiology in both AKI and non-AKI group. Viral encephalitis and scrub typhus was the etiology in majority of cases in our study. Majority of authors reported sepsis as a leading cause of AKI in their study. ${ }^{13,15-17,21}$ Others had reported pneumonia as a commonest etiology of AKI. ${ }^{19,20}$ In few studies hemato-oncologic diseases and postoperative cases were the commonest etiologies. ${ }^{18,20}$ These differences could be due to regional differences in study populations, varied disease etiology, difference in demographic
Table 4: Outcome of AKI and non-AKI children

\begin{tabular}{llll}
\hline Variables & $\begin{array}{l}A K I \\
n=86(\%)\end{array}$ & $\begin{array}{l}\text { Non- } A K I \\
n=275(\%)\end{array}$ & $p$ value \\
\hline Mortality & $30(34.8 \%)$ & $56(20.3 \%)$ & 0.005 \\
$\begin{array}{l}\text { Duration of mechanical } \\
\text { ventilation (days) }\end{array}$ & $5.2 \pm 1.6$ & $3.2 \pm 1.2$ & 0.001 \\
$\begin{array}{l}\text { Duration of PICU stay (days) } \\
\begin{array}{l}\text { Duration of hospital stay } \\
\text { (days) }\end{array}\end{array}$ & $6.3 \pm 1.9$ & $4.5 \pm 1.4$ & 0.001 \\
\hline
\end{tabular}

profile of critical disease, different admission criteria and admission policy in PICU. Eastern Utter Pradesh is high endemic area for viral encephalitis particularly during July to November months, therefore maximum cases in our study were of viral encephalitis. ${ }^{23}$ In last few years scrub typhus became a leading cause of encephalitis in this region. ${ }^{24}$ Scrub typhus was also reported as an important cause of AKI from different parts of India also. ${ }^{25-28}$ In our study within 24 hours and within 7 days of admission, AKI developed in $33.6 \%$ and $96.5 \%$ of children respectively. Other authors had also reported maximum children in their study developed AKI within 72 hours of admission. . $^{4,18,19,21,22}$

We studied the risk factors for the development of AKI in PICU children. Shock, high PRISM III score and longer duration of hospital stay were associated with development of AKI in our study. Similar results were reported by other authors also. 14,19,20

In present study AKI cases reached into $R_{\max } I_{\max }$ and $F_{\max }$ grading at some point of time during hospitalization in $53.4 \%$, $28 \%$ and $18.6 \%$ cases respectively. Other researchers also reported similar results. ${ }^{5,14-16,19,21}$ But in our study $R_{\max }$ cases were more than three times of $\mathrm{F}_{\max }$ cases, as seen by other author also. ${ }^{15}$

In our study the children who developed AKI during hospitalization had higher (34.8\%) mortality as compared to non AKI group (20.3\%) and this difference was statistically significant $(p=0.005)$. The duration on mechanical ventilation, PICU stay and hospital stay were also significantly $(p=0.001)$ higher in AKI children than in non-AKI. Similar results were reported by other authors also. $^{14,18,19,21,29}$

\section{Conclusion}

AKI is common in critically ill children and associated with high mortality and morbidity. It is associated with longer PICU and hospital stay, leading to a major burden on the healthcare system.

\section{References}

1. Andreoli S. Clinical evaluation and management. In: Avner E, Harmon W, Niaudet P, editors. Pediatric Nephrology. Philadelphia: Lippincott Williams and Wilkins; 2004. p. 1233-12352.

2. Schneider J, Khemani R, Grushkin C, Bart R. Serum creatinine as stratified in the RIFLE score for acute kidney injury is associated with mortality and length of stay for children in the pediatric intensive care unit. Crit Care Med. 2010;38:933-939.

3. Palmieri T, Lavrentieva A, Greenhalgh D. An assessment of acute kidney injury with modified RIFLE criteria in pediatric patients with severe burns. Intensive Care Med. 2009;35:2125-2129.

4. Thomas ME, Blaine C, Dawnay A, Devonald MA, Ftouh S, Laing C, et al. The definition of acute kidney injury and its use in practice. Kidney Int. 2015;87:62-73.

5. Akcan-Arikan A, Zappitelli M, Loftis LL, Washburn KK, Jefferson LS, Goldstein SL. Modified RIFLE criteria in critically ill children with acute kidney injury. Kidney Int. 2007;71:1028-1035. 
6. Kidney Disease: Improving Global Outcomes (KDIGO) Acute Kidney Injury Work Children. KDIGO clinical practice guideline for acute kidney injury. Kidney Int Suppl 2012;2:1-138.

7. Mehta RL, Kellum JA, Shah SV, Molitoris BA, Ronco C, Warnock DG, et al. Acute Kidney Injury Network: Report of an initiative to improve outcomes in acute kidney injury. Crit Care 2007;11:R31.

8. Mehta P, Sinha A, Sami A, Hari P, Kalaivani M, Gulati A, et al. Incidence of Acute Kidney Injury in hospitalized children. Ind Pediatr 2012;49(7):537-542.

9. Bandoria P, Bhagwat AG. Severity scoring systems in pediatric intensive care unit. Indian Journal of anesthesia. 2008;52:(5):663-675.

10. Prasad Gullipalli, Anjani A. Spectrum of Paediatric Acute Kidney Injury - A Referral Hospital Experience in a Developing Nation, Journal of Dental Medical Sciences (IOSR-JDMS) February 2015; 14(Issue 2): $80-87$.

11. Schwartz GJ, Muñoz A, Schneider MF. New equations to estimate GFR in children with CKD. Journal of the American Society of Nephrology. 2009:20(3):629-637.

12. Bowers LS, Wong ET. Kinetic serum creatinine assay II. A critical analysis and review. Clin Chem. 1980;26:555-561.

13. Restrepo de Rovetto C, Mora JA, Alexandre Cardona S, Marmolejo $\mathrm{AF}, \mathrm{Paz} \mathrm{JF}$, de Castaño I. Acute kidney injury applying pRifle scale in Children of Hospital Universitario del Valle in Cali, Colombia: clinical features, management and evolution. Colombia Médica. 2012 Jul;43(3):200-205.

14. Alkandari O, Eddington KA, Hyder A, Gauvin F, Ducruet T, Gottesman $\mathrm{R}$, et al. Acute kidney injury is an independent risk factor for pediatric intensive care unit mortality, longer length of stay and prolonged mechanical ventilation in critically ill children: a two-centre retrospective cohort study. Critical care. 2011 Jun;15(3):R146.

15. Krishnamurthy V, Shetty AK, Jaidev MD. Clinicoetiological profile of acute kidney injury in pediatric intensive care unit patients. Int J Contemp Pediatr 2016;3:1416-1418.

16. Wejdan Al-jboor, Reham Al mardini, Jwaher Al Bderat, Mahdi Frehat, Hazem Al Masri, Mohammad Saleh Alajloni. Acute Kidney Injury in Critically III Child. Saudi J Kidne Dis Transpl 2016;27(4):740-747.

17. Sriram Krishnamurthy, Parameswaran Narayanan, Sivaprakasam Prabha, Nivedita Mondal, Subramanian Mahadevan, NiranjanBiswal, et al. Clinical profile of acute kidney injury in a pediatric intensive care unit from Southern India: A prospective observational study. India J Crit Care Med. 2013 Jul-Aug;17(4):207-213.
18. Polo JG, Romero AA, Gil-Esparza MG, Cid JL, San Prudencio MG, Lafever SF, et al. Morbidity and mortality associated with acute kidney injury in patients admitted to pediatric intensive care units. Intensive medicine. 2014 Oct1;38(7):430-437.

19. Naik S, Sharma J, Yengkom R, Kalrao V, Mulay A. Acute kidney injury in critically ill children: Risk factors and outcomes. Indian J Crit Care Med 2014;18:129-133.

20. Mehta P, Sinha A, Sami A, Hari P, Kalaivani M, Gulati A, et al. Incidence of acute kidney injury in hospitalized children. Indian pediatrics. 2012 Jul 1;49(7):537-542.

21. Gupta S, Sengar GS, Meti PK, Lahoti A, Beniwal M, Kumawat M. Acute kidney injury in pediatric intensive care unit: Incidence, risk factors, and outcome. Indian J Crit Care Med 2016;20:526-529.

22. Miklaszewska M, Korohoda P, Sobczak A, Horbaczewska A, Filipiak A, Zachwieja $\mathrm{K}$, et al. Acute kidney injury in a single pediatric intensive care unit in poland: a retrospective study. Kidney and Blood Pressure Research. 2014;39(1):28-39.

23. Bhatt GC, Bondre VP, Sapkal GN, Sharma T, Kumar S, Gore MM, et al. Changing clinico-laboratory profile of encephalitis patients in the eastern Uttar Pradesh region of India. Tropical Doctor. 2012;42(2):106108.

24. Murhekar MV, Mittal M, Prakash JA, Pillai VM, Mittal M, Kumar CG,et al. Acute encephalitis syndrome in Gorakhpur, Uttar Pradesh, India-Role of scrub typhus. Journal of Infection. 2016 Dec 1;73(6):623-626.

25. Kumar V, Kumar V, Yadav AK, lyengar S, Bhalla A, Sharma N, et al. Scrub typhus is an under-recognized cause of acute febrile illness with acute kidney injury in India. PLoS neglected tropical diseases. 2014 Jan 30;8(1):e2605.

26. Kumar M, Krishnamurthy S, Delhi kumar CG, Narayanan P, Biswal N, Srinivasan S. Scrub typhus in children at a tertiary hospital in southern India: clinical profile and complications. Journal of infection and public health. 2012 Feb 1;5(1):82-88.

27. Attur RP, Kuppasamy S, Bairy M, Nagaraju SP, Pammidi NR, Kamath V, et al. Acute kidney injury in scrub typhus. Clinical and experimental nephrology. 2013 Oct 1;17(5):725-729.

28. Palanivel S, Nedunchelian K, Poovazhagi V, Raghunadan R, Ramachandran P. Clinical profile of scrub typhus in children. The Indian Journal of Pediatrics. 2012 Nov 1;79(11):1459-1462.

29. Alkandari O, Eddington KA, Hyder A, Gauvin F, Ducruet T, Gottesman $\mathrm{R}$, et al. Acute kidney injury is an independent risk factor for pediatric intensive care unit mortality, longer length of stay and prolonged mechanical ventilation in critically ill children: A two centre retrospective cohort study. Critical Care 2011;15:R146. 